\title{
Difference in responses between dogs and cats to large doses of gastrin on gastric secretion
}

\author{
SVERRE EMÅS AND MORTON I. GROSSMAN \\ From the Veterans Administration Center, Los Angeles, California, and the \\ Departments of Medicine and Physiology, UCLA Medical School, Los Angeles, California
}

EDITORIAL COMMENT In dogs the rapid injection of gastrin causes marked inhibition of induced acid secretion, but in cats there was increased secretion as occurs in man. This reaction in cats was abolished by truncal vagotomy.

We (Emås and Grossman, 1967a) recently reported that in conscious dogs supramaximal doses of gastrin extract caused a downward inflection in the doseresponse curve for acid secretion whereas in conscious cats maximal and supramaximal doses were equally effective, resulting in a plateau of the doseresponse curve. Our finding in cats agreed with that reported in man (Barabas, Payne, Johnston, and Burns, 1966). The inflection of the dose-response curve in dogs could be due to the inhibitory effect of large doses of gastrin on acid secretion that has been demonstrated in this species (Gillespie and Grossman, 1963; Gregory and Tracy, 1964; Konturek and Grossman, 1965). Conversely, the absence of the inflection of the dose-response curve in cats could indicate that large doses of gastrin in cats, as in man (Makhlouf, McManus, and Card, 1966), do not inhibit acid secretion.

The present study was designed to determine if a species difference exists between conscious dogs and cats in the effect of a rapid injection of a large dose of gastrin extract on acid and pepsin secretion. The results prompted us to repeat the study after truncal vagotomy.

\section{METHODS}

In four adult mongrel dogs $(11.6$ to $15.0 \mathrm{~kg}$., mean $13.3 \mathrm{~kg}$.) and four cats $(3.2$ to $4.8 \mathrm{~kg}$., mean $3.8 \mathrm{~kg}$.) gastric cannulas were inserted just proximal to the pyloric gland area near the greater curvature. The type of cannula used in the dogs was described by Thomas (1941) and that in the cats by one of us (Emås, 1960). Secretory studies were started three weeks after surgery.

After the conclusion of the first series of studies bilateral truncal vagotomy was performed under artificial respiration through an incision between the seventh and eighth left rib. Two or $3 \mathrm{~cm}$. of each trunk was resected. Following the vagotomy three of four cats accumulated balls of hair in the stomach. The hair was removed through a gastrotomy and a pyloroplasty was performed as described previously (Emås, 1964). Despite the pyloroplasty one cat reaccumulated hair in the stomach and was sacrificed. The secretory tests were resumed three weeks after the vagotomy and were completed within a period of six months.

The animals were deprived of food for at least 18 hours before each test but had free access to water. No animal was tested more than twice a week. All animals underwent the same number of tests.

The effect of a rapid intravenous injection of a large dose of gastrin extract on acid and pepsin secretion was tested against a background secretion stimulated by a continuous intravenous infusion of histamine or gastrin extract. The gastrin was prepared from hog antral mucosa according to the method of Gregory and Tracy (1964) but carried only through the isopropanol stage. The same batch of gastrin was used in all experiments. Throughout the tests $0 \cdot 15 \mathrm{M}$ sodium chloride solution was continuously infused intravenously by a peristaltic pump (Harvard Apparatus Co., Dover, Mass.) at a rate of $32 \mathrm{ml}$. per hour in the dogs and $14 \mathrm{ml}$. per hour in the cats. After two to four 15-minute collections of basal secretion histamine or gastrin was added to the infusion. In both the dogs and cats histamine was administered in a dose of $0.08 \mathrm{mg}$. of the dihydrochloride per kilogram body weight per hour and gastrin extract in a dose of $0.8 \mathrm{~g}$. per kilogram body weight per hour. The dose of the gastrin extract refers to grams wet weight antral mucosa extracted. According to previously published dose-response curves for acid secretion in conscious dogs and cats with gastric fistulas (Emås et al., 1967a), these doses of histamine or gastrin extract produce acid responses that are about 85 to $95 \%$ of the maximal response. This was confirmed in preliminary experiments on the dogs. All four of the cats in the present study had been used in the previous study (Emås et al., 1967a). The rate of secretion of acid reached a plateau one hour after starting infusion of the stimulant and remained nearly constant for at least another hour. Two hours after the start of the infusion gastrin extract was rapidly injected 
intravenously in a dose of 3.2 or $6.4 \mathrm{~g}$. per $\mathrm{kg}$. body weight. If not otherwise stated the dose rapidly injected is $3.2 \mathrm{~g}$. per $\mathrm{kg}$. body weight. Both doses of gastrin are supramaximal for acid secretion when infused intravenously for one hour (Emås et al., 1967a). No side effects of the rapid gastrin injections were observed. In control experiments the large dose of gastrin was substituted by the corresponding volume of saline $(0.32 \mathrm{ml}$. per $\mathrm{kg}$. body weight). The continuous background stimulation with histamine or gastrin continued for an additional three hours after the rapid injection.

2-Deoxy-D-glucose (2-DG) (Sigma Chemical Co., St. Louis, Missouri) was used to test the completeness of the vagotomy (Eisenberg, Emås, and Grossman, 1966). In both the dogs and cats 2-DG freshly dissolved in saline (1 ml. per kg. body weight) was given as a single intravenous injection in a dose of $100 \mathrm{mg}$. per $\mathrm{kg}$. body weight. Gastric secretion was collected for four hours following the injection. To confirm that the vagotomy remained complete throughout the series of studies the last experiment with 2-DG was carried out after conclusion of the studies with histamine and gastrin.

Gastric juice was collected every $15 \mathrm{~min}$. and the volume recorded. The acid concentration of the collections was determined by titration (autoburet titrator) of $0.2 \mathrm{ml}$. of gastric juice to $p \mathrm{H} 7$ (Radiometer, Copenhagen, Denmark) using 0.2 N NaOH. Pepsin concentration was determined in samples combined from two consecutive 15-min. collections during the second through the fourth hour of infusion of histamine or gastrin. The method of Grossman and Marks (1960) with radioiodinated albumin as substrate was used for the pepsin determinations. The mean 15-min. output of acid or pepsin in response to histamine or gastrin during the hour before the rapid injection of gastrin or saline is referred to as the $100 \%$ level or the pre-injection level. The 15 -min. acid outputs during the hour preceding and during the three hours following the rapid injection are expressed as percentages of the pre-injection level; similarly, the mean 15-min. outputs of pepsin for each 30-min. period are expressed as percentages of the pre-injection level. To evaluate the effect of the rapid gastrin injection on acid and pepsin secretion, the percentage outputs in the test and control experiments were compared using the U-test (Siegel, 1956).

\section{RESULTS BEFORE VAGOTOMY}

ACID RESPONSE TO 2-DG The intravenous injection of 2-DG (100 mg. per $\mathrm{kg}$. body weight) increased acid output in both dogs and cats within the first 15-min. period (Fig. 1). The mean peak acid output in dogs was in the second and in cats in the fourth post-injection period. The mean peak acid output in dogs (6.24 mEq. per $15 \mathrm{~min}$.) was five to six times higher than in cats $(1.16 \mathrm{mEq}$. per $15 \mathrm{~min})$. Four hours after the injection the acid secretion was still increased in dogs but had returned to basal level in cats.

HISTAMINE-STIMULATED ACID SECRETION In dogs the rapid gastrin injection produced a marked inhibition of histamine-stimulated acid secretion (Fig. 2, left). The inhibition was greatest, $81 \%$, in the first $15-\mathrm{min}$. post-injection period, corresponding to a reduction in acid output from a pre-injection level of $6.92 \mathrm{mEq}$. per $15 \mathrm{~min}$. to $1.29 \mathrm{mEq}$. per $15 \mathrm{~min}$. Secretion was markedly inhibited for another 15 min.-period and full recovery had occurred within the first postinjection hour. In sharp contrast to the effect in dogs, the gastrin injection produced a marked increase of
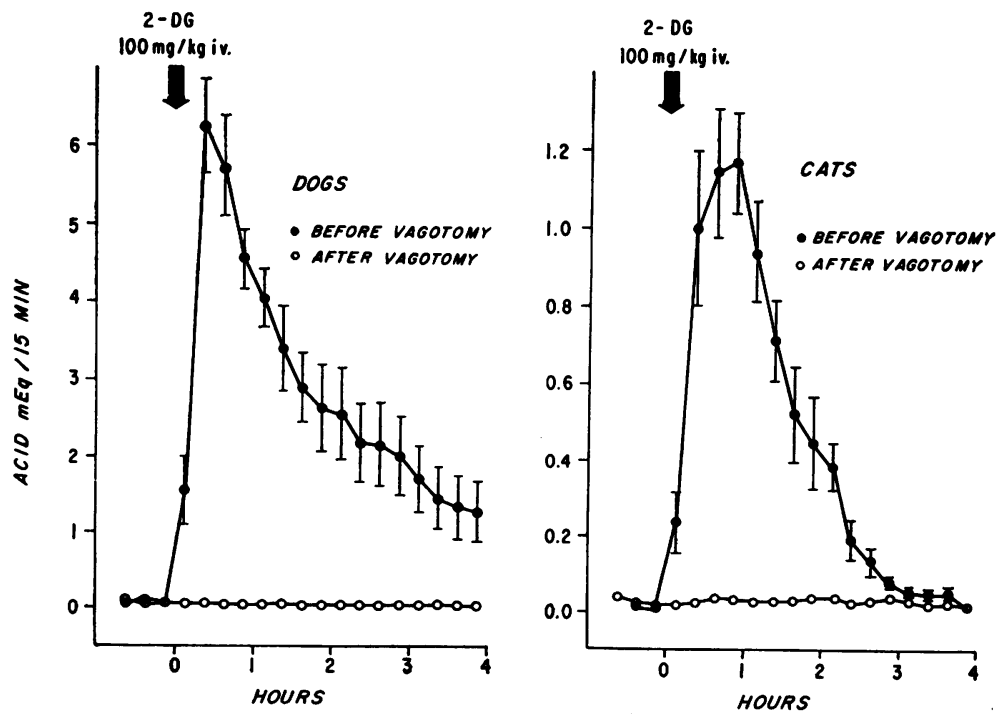

FIG. 1. Effect of truncal vagotomy on the acid response to 2-DG in four dogs (left) and three cats (right) with gastric fistulas. Each animal was tested twice before and three times after the vagotomy. Vertical bars represent standard error of the mean. 

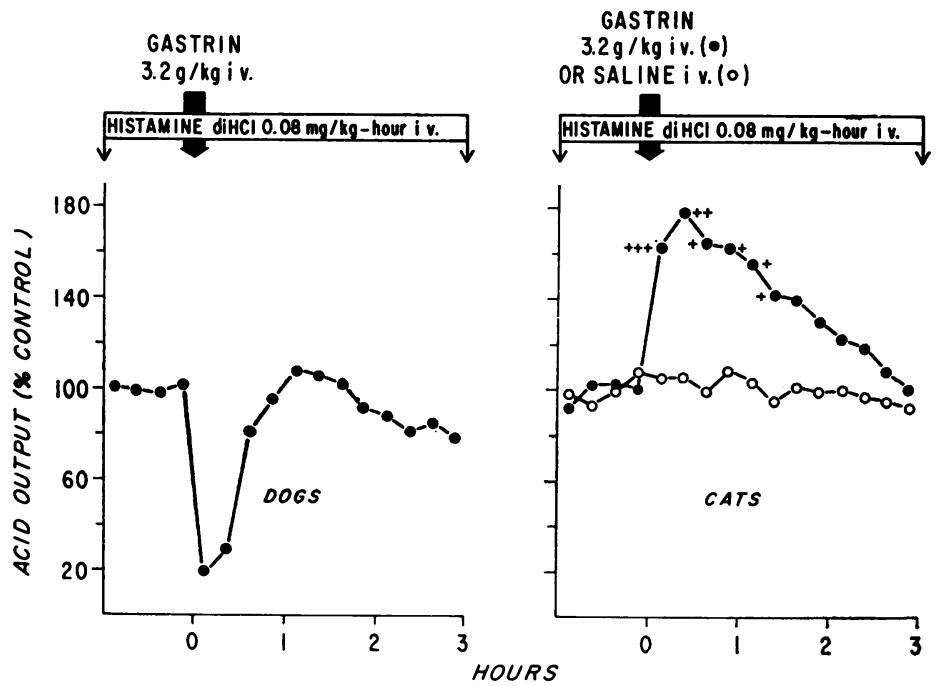

FIG. 2. Effect of rapid intravenous injection of a large dose of gastrin extract or of saline on histamine-stimulated acid secretion in four dogs (left) and four cats (right) with gastric fistulas. In this and subsequent figures each curve represents the mean of two experiments on each animal. The degree of significance of the difference between the percentage response in experiments with rapid gastrin and rapid saline injection is indicated as follows: no plus, $p>0.05,+$, $0.01<p<0.05 ;++, 0.001<p$ $<0.01$; ++ +, $p<0.001$.

acid secretion in cats (Fig. 2, right). In the first 15 min. post-injection period acid output was $163 \%$ and in the second period it reached its peak, $178 \%$ of the pre-injection level. During the period of peak secretion the acid output was $1.90 \mathrm{mEq}$. per $15 \mathrm{~min}$. or $0.83 \mathrm{mEq}$. over the pre-injection level $(1.07 \mathrm{mEq}$. per $15 \mathrm{~min}$.). The percentage output following the gastrin injection was significantly $(P<0.001$ to $P<0.05)$ elevated over the output in the control experiments for 1.5 hours. Throughout the control experiments the acid output remained close to the $100 \%$ level ( $1.06 \mathrm{mEq}$. per $15 \mathrm{~min}$.).

GASTRIN-STIMULATED ACID SECRETION In dogs (Fig. 3 , left) the rapid gastrin injection reduced acid secretion to $43 \%$ of the pre-injection level or from $7 \cdot 17 \mathrm{mEq}$. per $15 \mathrm{~min}$. to $3.11 \mathrm{mEq}$. per $15 \mathrm{~min}$. Secretion then remained low throughout the remainder of the test but the reduction was significant
( $\mathrm{P}<0.001$ and $\mathrm{P}<0.01)$ only during the first postinjection hour. In the control experiments the mean acid output during the hour before the rapid saline injection was $7 \cdot 10 \mathrm{mEq}$. per 15 minutes. Acid output then declined with time to $50 \%$ of the pre-injection level. In cats (Fig. 3, right) the rapid gastrin injection increased acid output during the first and second post-injection periods from a pre-injection level of $1.42 \mathrm{mEq}$. per $15 \mathrm{~min}$. to about $112 \%$ of that level. Compared with the control experiments the gastrin injection significantly $(P<0.001$ and $P<0.05)$ increased the percentage output during the second and third periods. In cats, as in dogs, the acid output in the control experiments (pre-injection level 1.22 mEq. per $15 \mathrm{~min}$.) declined with time by about $50 \%$.

HISTAMINE-STIMULATED PEPSIN SECRETION The mean pepsin output in response to continuous histamine during the hour before the rapid injection was 561
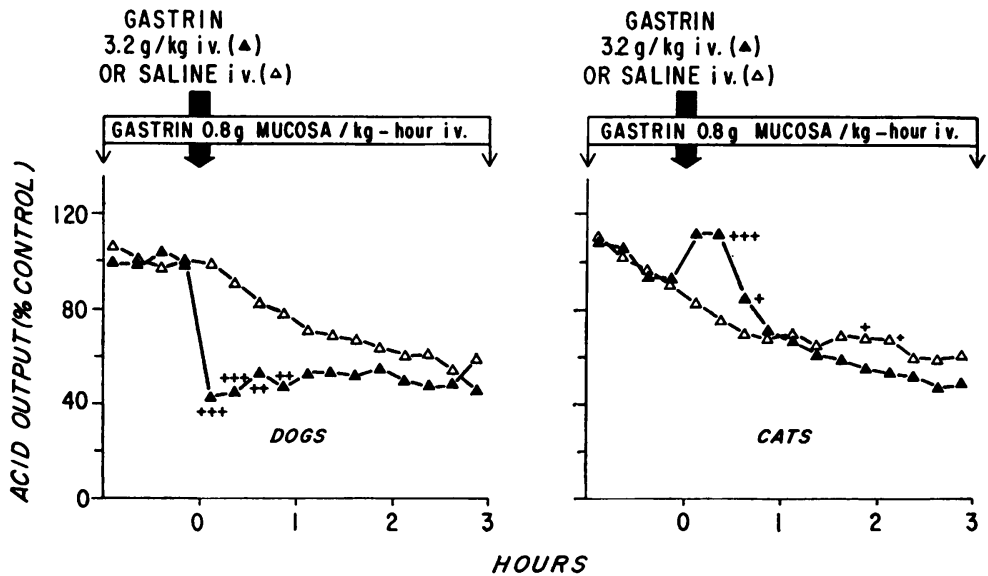

FIG. 3. Effect of rapid intravenous injection of a large dose of gastrin extract or of saline on gastrin-stimulated acid secretion in four dogs (left) and four cats (right) with gastric fistulas. 


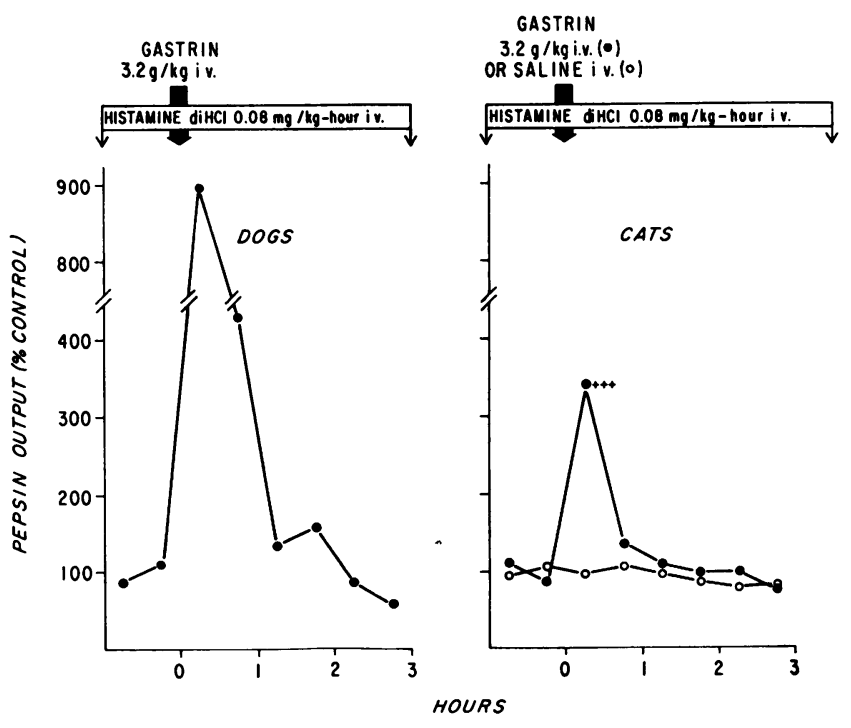

FIG. 4. Effect of rapid intravenous injection of a large dose of gastrin extract or of saline on histamine-stimulated pepsin secretion in four dogs (left) and four cats (right) with gastric fistulas.

pepsin units per $15 \mathrm{~min}$. or about the same as during basal conditions without stimulation (Emås et al., 1967a). Despite a marked inhibition of histaminestimulated acid secretion and volume flow rate the rapid gastrin injection produced a pronounced increase of pepsin secretion in dogs (Fig. 4, left). In the first $30 \mathrm{~min}$. post-injection period the mean pepsin output was $895 \%$ of the pre-injection level or 5,021 pepsin units per $15 \mathrm{~min}$. The mean pepsin output remained elevated for another $30-\mathrm{min}$. period but had returned essentially to the pre-injection level one hour after the injection. The gastrin injection had the same effect on pepsin secretion in cats (Fig. 4, right) as in dogs; mean pepsin output increased to $340 \%$ of the pre-injection level in $30 \mathrm{~min}$. or from 133 pepsin units per $15 \mathrm{~min}$. to 451 units per 15 minutes. The percentage output differed significantly $(P<0.001)$ from that in the control experiments. Pepsin secretion returned to the pre-injection level in the next 30-min. period. In the control experiments the mean pepsin output during the hour before the rapid saline injection was 299 units per 15 minutes. Pepsin output remained nearly constant throughout the control experiments. In cats, as in dogs, the pepsin output during the hour before the rapid injections did not differ from the output under basal conditions without stimulation (Emås et al., 1967a).

GASTRIN-STIMULATED PEPSIN SECRETION In dogs the pepsin output in response to continuous gastrin was about three times the output to histamine; the mean pre-injection level was 1,658 pepsin units per $15 \mathrm{~min}$.

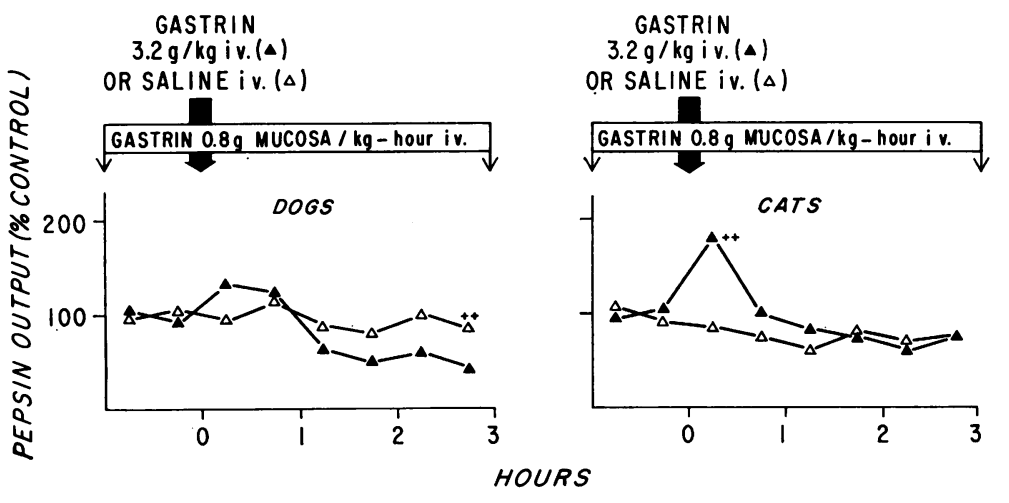

FIG. 5. Effect of rapid intravenous injection of a large dose of gastrin extract or of saline on gastrin-stimulated pepsin secretion in four dogs (left) and four cats (right) with gastric fistulas. 

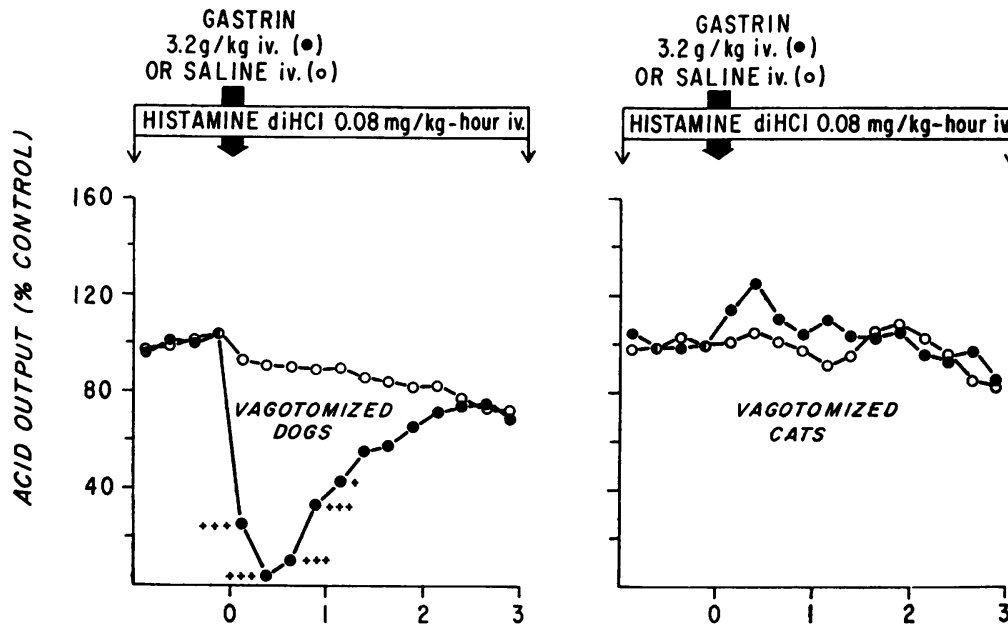

FIG. 6. Effect of rapid

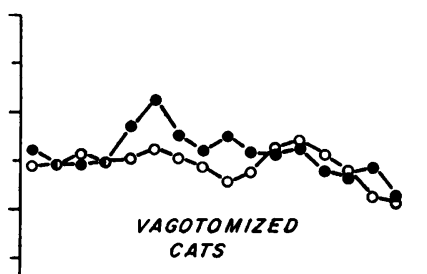
intravenous injection of a large dose of gastrin extract or of saline on histamine-stimulated acid secretion in four vagotomized dogs (left) and three vagotomized cats (right) with gastric fistulas. CATS

in the experiments with the rapid gastrin injection and 1,284 units per min. in the control experiments. The rapid gastrin injection did not significantly (P $>0.05)$ alter pepsin output (Fig. 5, left). Pepsin secretion remained nearly constant in the control experiments. In cats the mean pepsin output in response to the background dose of gastrin was about four times the output to histamine or 942 and 704 pepsin units per $15 \mathrm{~min}$. during the hour before the rapid injection of gastrin and saline, respectively. The rapid gastrin injection increased pepsin output in the cats by $81 \%(p<0.01)$ in the first $30-\mathrm{min}$. period or from 942 pepsin units per $15 \mathrm{~min}$. to 1,700 units per $15 \mathrm{~min}$. (Fig. 5, right). Pepsin secretion returned to the pre-injection level in the next 30-min. period. There was a slight decline in pepsin output with time in the control experiments.

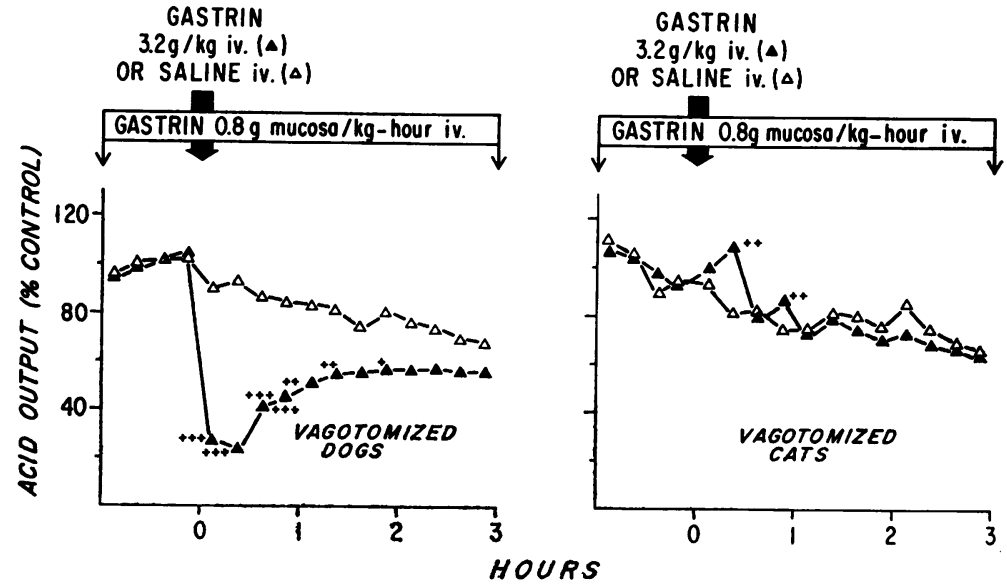

FIG. 7. Effect of rapid intravenous injection of a large dose of gastrin extract or of saline on gastrin-stimulated acid secretion in four vagotomized dogs (left) and three vagotomized cats (right) with gastric fistulas. 
cantly $(P<0.001$ and $P<0.05)$ lower than in the control experiments for more than one hour. The acid output progressively declined in the control experiments. In the three cats tested after vagotomy the pre-injection level in the experiments with rapid gastrin and saline injection was 1.07 and $1.09 \mathrm{mEq}$. per 15 minutes. The rapid gastrin injection did not significantly $(P=0 \cdot 2)$ alter acid output (Fig. 6, right). In two experiments on each cat gastrin in a dose of $6.4 \mathrm{~g}$. per $\mathrm{kg}$. body weight was rapidly injected intravenously. Peak mean acid output following the injection, $140 \%$ of the pre-injection level $(0.92 \mathrm{mEq}$. per $15 \mathrm{~min}$ ), occurred in the second 15-min. period. The increase was not significant $(P>0 \cdot 1)$.

GASTRIN-STIMULATED ACID SECRETION The rapid gastrin injection reduced gastrin-stimulated acid secretion in dogs to about $25 \%$ of the pre-injection level in the first and second 15-min. periods (Fig. 7, left) or, in the first period, from $4.70 \mathrm{mEq}$. to 1.30 $\mathrm{mEq}$. The percentage acid output was significantly $(P<0.001$ to $P<0.05)$ lower than in the control experiments for more than 1.5 hours. The preinjection level in the control experiments was 5.32 mEq. per $15 \mathrm{~min}$. Acid output progressively declined to about $70 \%$ of the pre-injection level at the end of the experiments. In cats (Fig. 7, right) the rapid gastrin injection slightly increased acid output to a maximum of $108 \%$ of the pre-injection level in the second post-injection period. Although the increase was small, it differed significantly $(P<0.01)$ from the acid output in the control experiments. The preinjection level was the same in the test and control experiments ( $1.00 \mathrm{mEq}$. per $15 \mathrm{~min}$.). In the control experiments the acid response progressively decreased to the same extent as in dogs.

hISTAMINE-STIMULATED PEPSIN SECRETION In dogs the pre-injection level was 628 pepsin units per 15 min. before the rapid gastrin injection and 753 units per $15 \mathrm{~min}$. before the rapid saline injection, or four to five times the output in basal unstimulated vagotomized dogs (Emås et al., 1967a). The gastrin injection increased pepsin output to a maximum of $327 \%$ of the pre-injection level $(P<0.01)$ in the second 30-min. period (Fig. 8, left) or to 2,052 pepsin units per 15 minutes. Two hours after the gastrin injection the percentage pepsin output in the test and control experiments were the same. Pepsin output tended to increase with time in the control experiments. In cats the rapid gastrin injection increased pepsin output to $450 \%$ of the pre-injection level (Fig. 8, right) or from 99 to 444 pepsin units per 15 minutes. Pepsin secretion had returned to the preinjection level in the next $30-\mathrm{min}$. period. The percentage pepsin output during the first $30-\mathrm{min}$. period after the gastrin injection differed significantly ( $P$ $<0.01)$ from the output after the saline injection. The effect of a rapid intravenous injection of $6 \cdot 4 \mathrm{~g}$. of gastrin per $\mathrm{kg}$. body weight on pepsin secretion was almost identical with the effect of $3 \cdot 2 \mathrm{~g}$. per $\mathrm{kg}$. Pepsin output increased significantly to $400 \%$ $(P<0.01)$ of the pre-injection level in the first 30 min. post-injection period and to $173 \%(P<0.05)$ in the second period. In the subsequent $30-\mathrm{min}$. period the percentage output did not differ significantly $(P=0 \cdot 1)$ from the output in the control experiments. In the control experiments the pepsin output tended

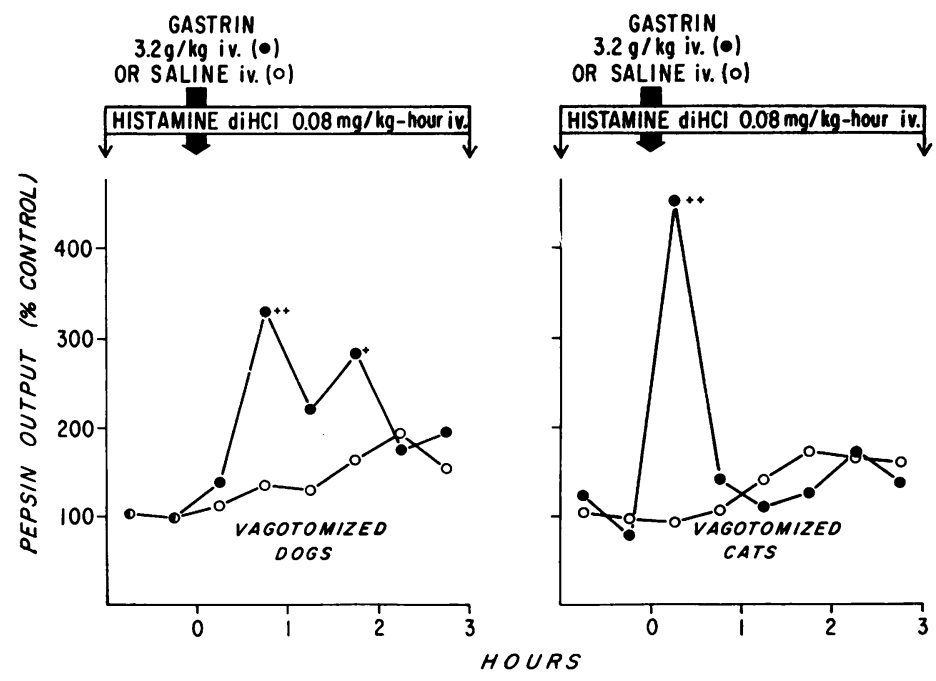

FIG. 8. Effect of rapid intravenous injection of a large dose of gastrin extract or of saline on histamine-stimulated pepsin secretion in four vagotomized dogs (left) and three vagotomized cats (right) with gastric fistulas. 


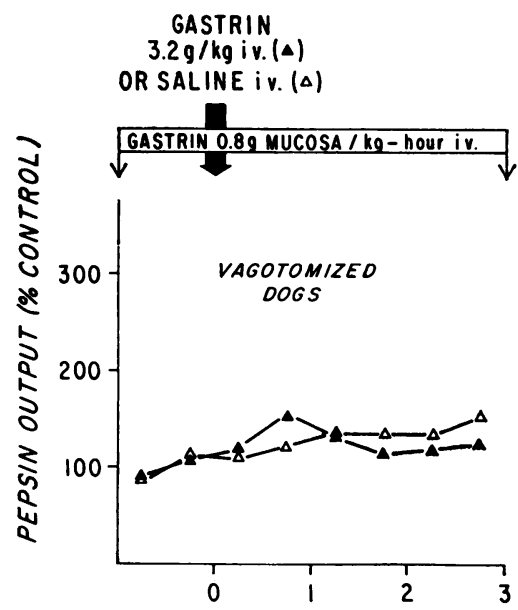

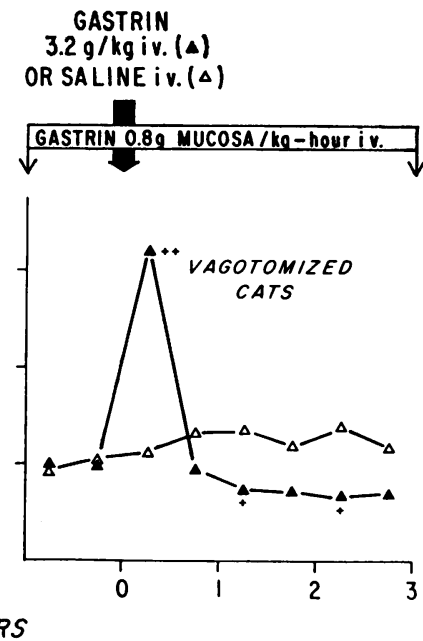

FIG. 9. Effect of rapid intravenous injection of a large dose of gastrin extract or of saline on gastrin-stimulated pepsin secretion in four vagotomized dogs (left) and three vagotomized cats (right) with gastric fistulas. to increase with time. The pepsin output during the pre-injection hour was six to eight times the output in basal unstimulated vagotomized cats (unpublished data).

GASTRIN-STIMULATED PEPSIN SECRETION The preinjection level in both the test and control experiments on dogs was about three times and on cats two to three times as high as when histamine was used as the background stimulus. The rapid gastrin injection did not significantly $(\mathrm{P}>\mathbf{0 . 2})$ alter pepsin output in dogs (Fig. 9, left). In cats the rapid gastrin injection significantly $(P<0.01)$ increased pepsin output during the first $30-\mathrm{min}$. period to $323 \%$ of the pre-injection level, or from 244 to 789 pepsin units per $15 \mathrm{~min}$. (Fig. 9, right). Secretion returned to the pre-injection level in the subsequent $30-\mathrm{min}$. period.

\section{DISCUSSION}

2-DG is a potent vagal stimulant of acid secretion in cats as well as in dogs. As in dogs (Eisenberg et al., 1966), the onset of the acid response to 2-DG in cats is faster than that to insulin (Emås, 1963). The previous finding that truncal vagotomy eliminated the acid response to 2-DG in dogs (Emås and Grossman, 1967b) was confirmed and a similar result was seen in cats. In both species the effect of the vagotomy remained throughout the series of experiments.

The effects of the rapid intravenous injection of gastrin $(3 \cdot 2 \mathrm{~g}$. per $\mathrm{kg}$. body weight) on acid and pepsin secretion in the dogs and cats are summarized in Table $\mathrm{I}$.

Before vagotomy the rapid injection produced marked inhibition of histamine- and gastrin-
TABLE I

EFFECTS OF A RAPID INTRAVENOUS INJECTION OF A LARGE DOSE OF GASTRIN EXTRACT ( $3 \cdot 2$ G. PER KG. BODY WEIGHT) ON HISTAMINE- AND GASTRIN-STIMULATED ACID AND PEPSIN SECRETION IN CONSCIOUS DOGS AND CATS WITH GASTRIC FISTULAS

\begin{tabular}{|c|c|c|c|c|c|}
\hline \multirow{2}{*}{$\begin{array}{l}\text { Background } \\
\text { Stimulation }\end{array}$} & \multirow{2}{*}{$\begin{array}{l}\text { Secre- } \\
\text { tion }\end{array}$} & \multicolumn{2}{|l|}{ Dogs } & \multicolumn{2}{|l|}{ Cats } \\
\hline & & $\begin{array}{l}\text { Before } \\
\text { Truncal } \\
\text { Vagotomy }\end{array}$ & $\begin{array}{l}\text { After } \\
\text { Truncal } \\
\text { Vagotomy }\end{array}$ & $\begin{array}{l}\text { Before } \\
\text { Truncal } \\
\text { Vagotomy }\end{array}$ & $\begin{array}{l}\text { After } \\
\text { Truncal } \\
\text { Vagotomy }\end{array}$ \\
\hline $\begin{array}{l}\text { Histamine } \\
\text { Gastrin extract } \\
\text { Histamine } \\
\text { Gastrin extract } \\
\uparrow=\text { increase; } 0=\end{array}$ & $\begin{array}{l}\text { Acid } \\
\text { Acid } \\
\text { Pepsin } \\
\text { Pepsin } \\
\text { = unalter }\end{array}$ & $\begin{array}{l}\uparrow \\
0 \\
d ;\end{array}$ & $\begin{array}{c}\downarrow \\
\uparrow \\
0 \\
\text { reas }\end{array}$ & $\uparrow$ & $\begin{array}{l}\mathbf{0} \\
\mathbf{0}(\uparrow) \\
\uparrow \\
\uparrow\end{array}$ \\
\hline
\end{tabular}

stimulated acid secretion in dogs, confirming the finding of Konturek et al. (1965); in cats it produced stimulation. With gastrin as the background stimulus the increase was small, merely counteracting the decrease with time of the acid response to the continuous gastrin infusion. With histamine as the background stimulus the mean peak acid output following the rapid gastrin injection was higher than with gastrin as the background stimulus and higher than could be attained by either histamine or gastrin alone in the same cats (Emås and Grossman, 1967a). This suggests true potentiation between histamine and gastrin in stimulation of acid secretion in the vagally innervated cat stomach. Potentiation between these stimulants has previously been demonstrated in the vagally denervated oxyntic gland in dogs (Passaro, Gillespie, and Grossman, 1963). In cats, however, the vagus nerves appear to be implicated in the potentiating action since vagotomy abolished the stimulatory effect of the rapid gastrin injection on histamine-stimulated acid secretion. It 
was not restored by doubling the gastrin dose for the rapid injection, nor did that dose produce any inhibition of acid secretion. After vagotomy, as before vagotomy, the rapid gastrin injection produced a small increase of gastrin-stimulated acid secretion in cats which was significant only because of a progressive decline in acid output with time in the control experiments. In dogs the inhibitory action of the rapid gastrin injection was even more pronounced after vagotomy than before. Inhibition of acid secretion by a rapid injection of a large dose of gastrin has previously been demonstrated in the vagally denervated oxyntic gland pouch of dogs (Gillespie et al., 1963; Gregory et al., 1964; Konturek et al., 1965).

The inhibitory action of a large dose of gastrin on gastrin-stimulated acid secretion in dogs and the absence of the inhibitory action in cats might explain why supramaximal doses of gastrin (for acid secretion) produce submaximal acid responses in dogs but maximal acid responses in cats (Emås et al., 1967a).

The progressive decline with time of the acid output in response to continuous gastrin has been observed previously in conscious cats (Emås, 1962). The present findings exclude the possibility that this phenomenon is due to an inhibitory action of gastrin. Apparently the progressive decrease in secretion that occurs during continuous intravenous infusion of gastrin represents a decrease in sensitivity to gastrin rather than a decrease in secretory capacity. With respect both to the shape of the dose-response curve to gastrin (Emås et al., 1967a) and to the effect of a rapid injection of a large dose of gastrin on acid secretion our findings on cats differ from those on dogs but are in agreement with those reported on man (Barabas et al., 1966; Makhlouf, et al., 1966). The present study offers no explanation for the inhibitory action of gastrin on acid secretion in dogs. It seems, however, justifiable to consider this inhibition by gastrin as a species peculiarity without known physiological significance. In studies thus far reported endogenously released gastrin has failed to inhibit histamine- and gastrin-stimulated acid secretion in dogs (Passaro and Goodman, 1965; Quintana, De la Rosa, and Dragstedt, 1965) presumably because of too small amounts of gastrin being released.

Before vagotomy the dose of histamine used as background stimulation was supramaximal for pepsin secretion in both dogs and cats (Emås and Grossman, 1967a) and did not increase pepsin output over basal level in either species. Despite the different effects of the rapid gastrin injection on histamine-stimulated acid secretion in dogs and cats it increased pepsin secretion in both species. In cats the increase was moderate, not exceeding the maximal output to a continuous infusion of gastrin alone (Emås et al., 1967a). In dogs, on the other hand, the rapid gastrin injection against background stimulation with histamine produced a marked increase in pepsin output despite a marked inhibition in acid and volume output. During the period of peak pepsin secretion the pepsin output in the dogs was twice the maximal output to gastrin alone and 10 times the maximal output to histamine alone (Emås and Grossman, 1967a). Against a background stimulation with gastrin in a dose that caused maximal pepsin secretion (Emås et al., 1967a) the rapid gastrin injection did not significantly increase pepsin output in the dogs. The results therefore suggest a potentiating action of histamine and gastrin on pepsin secretion in dogs. The results also demonstrate that pepsin secretion can be activated independently of acid secretion. In cats there was no evidence for a potentiating action of histamine and gastrin on pepsin secretion, since the peak output of pepsin after a rapid gastrin injection was almost four times as high when gastrin was used as background stimulus as it was with histamine background.

After vagotomy the background stimulation with histamine produced a higher pepsin output in dogs and a lower pepsin output in cats than before vagotomy. This is in agreement with our findings that after truncal vagotomy higher doses of histamine were required for maximal pepsin response in dogs (Emås et al., 1967b) whereas in cats vagotomy almost abolished the effect of histamine on pepsin secretion (unpublished data). With histamine as the background stimulus the rapid gastrin injection increased pepsin output in the vagotomized dogs to approximately the level produced by gastrin as background stimulus. Accordingly, we conclude that in the vagotomized dogs the increase in pepsin output caused by the rapid injection probably is not the result of a potentiating action of histamine and gastrin on pepsin secretion but rather is an additive effect. An increase of pepsin output following a rapid gastrin injection against background stimulation with histamine has been demonstrated from vagally denervated oxyntic gland pouches in dogs (Gregory et al., 1964). Also in the vagotomized cats the effect of the rapid gastrin injection against a background stimulation with histamine is more in accordance with an additive effect of histamine and gastrin on pepsin secretion.

Background stimulation with gastrin produced almost the same pepsin output before and after vagotomy in dogs whereas in cats the pepsin response after the vagotomy was about one-fourth of the prevagotomy response. This is in agreement with our 
findings that the pepsin responses to large doses of gastrin are affected little or not at all by vagotomy in dogs (Emås et al., 1967b) but are markedly reduced in cats (unpublished data). Against background stimulation with gastrin the rapid gastrin injection did not significantly alter the pepsin output in the vagotomized dogs presumably because the dose of gastrin used for background stimulation produced close to maximal response. In the vagotomized cats, on the other hand, the same dose of gastrin for background stimulation as used in the dogs did not produce maximal pepsin response (unpublished data) and here the rapid gastrin injection increased pepsin output. This interpretation is in accordance with the observations of Gregory et al., (1964) that a rapid gastrin injection produced a larger increase in pepsin output from vagally denervated oxyntic gland pouches in dogs continuously stimulated by low than by high doses of gastrin.

\section{SUMMARY}

The effect of a rapid intravenous injection of a large dose of gastrin extract on gastric secretion induced by a background stimulation with histamine or gastrin was compared in conscious dogs and cats with gastric fistulas. In dogs the rapid gastrin injection markedly inhibited acid secretion induced by histamine or gastrin. The inhibition became even more pronounced after truncal vagotomy. In cats the rapid injection against background stimulation with histamine markedly increased acid secretion, presumably by a potentiating action of histamine and gastrin. Against background stimulation with gastrin the rapid injection increased acid secretion to preinjection levels in cats. Truncal vagotomy abolished the effect of the rapid injection on acid secretion in cats.

Despite the marked difference between dogs and cats in the effect on acid secretion, rapid gastrin injection against background stimulation with histamine increased pepsin secretion in both species. The increase in pepsin secretion was marked in dogs, moderate in cats. The increase remained after truncal vagotomy. Against background stimulation with gastrin the rapid gastrin injection did not alter pepsin secretion in dogs but moderately increased it in cats. The same results were obtained after truncal vagotomy.

The technical assistance of Albert Skulsky, John Washington, and Raymond Lichter is gratefully acknowledged. This work was supported in part by U.S.P.H.S. grant AM 8354.

\section{REFERENCES}

Barabas, A. P., Payne, R. A., Johnston, 1. D. A., and Burns, G. P. 1966). The effect of vagotomy on gastrin-stimulated gastricacid secretion in man. Lancet, 1, 118-119.

Eisenberg, M. M., Emås, G. S., and Grossman, M. I. (1966). Comparison of the effect of 2-deoxy-D-glucose and insulin on gastric acid secretion in dogs. Surgery, 60, 111-117.

Emås, S. (1960). Gastric secretory responses to repeated intravenous infusions of histamine and gastrin in nonanesthetized and anesthetized gastric fistula cats. Gastroenterology, 39, 771-782.

-, (1962). Effect of acetazolamide on histamine-stimulated and gastrin-stimulated gastric secretion. Ibid., 43, 557-563.

-, (1963). Gastric acid secretion in gastric fistula cats during reserpine treatment. Acta physiol. scand., 59, 169-183.

after vagotomy and in vagotomized gastric fistula cats during reserpine treatment. Ibid., 61, 255-271.

- , and Grossman, M. I. (1967a). Comparison of gastric secretion and conscious dogs and cats. Gastroenterology, 52, 29-34.

acid and pepsin responses to histamine and gastrin in dogs. Amer. J. Physiol., In press.

Gillespie, I. E., and Grossman, M. I. (1963). Inhibition of gastric secretion by extracts containing gastrin. Gastroenterology, 44, 301-310.

Gregory, R. A., and Tracy, H. J. (1964). The constitution and properties of two gastrins extracted from hog antral mucosa. Gut, 5, 103-117.

Grossman, M. I., and Marks, I. N. (1960). Secretion of pepsinogen by the pyloric glands of the dog with some observations on the histology of the gastric mucosa. Gastroenterology, 38, 343-352.

Konturek, S., and Grossman, M. I. (1965). Effect of large dose of gastrin I on pepsin secretion. Proc. Soc. exp. Biol. (N.Y.), 119, 443-444.

Makhlouf, G. M., McManus, J. P. A., and Card, W. I. (1966). Action of gastrin II on gastric secretion in man. In Gastrin, edited by M. I. Grossman, pp. 139-169. University of California Press, Berkeley. Butterworth, London.

Passaro, E. P., Jr., Gillespie, I. E., and Grossman, M. I. (1963). Potentiation between gastrin and histamine in stimulation of gastric secretion. Proc. Soc. exp. Biol. (N.Y.), 114, 50-52.

- , and Goodman, G. (1965). Effects of endogenous gastrin on acid response to histamine and gastrin. Surg. Forum, 16, 313.

Quintana, R. B., De la Rosa, C., and Dragstedt, L. R. (1965). The effect of endogenous gastrin on histamine-induced gastric secretion. Amer. J. dig. Dis., 10, 745-750.

Siegel, S. (1956). Nonparametric Statistics for the Behavioral Sciences., P. 116. McGraw-Hill, New York.

Thomas, J. E. (1941). An improved cannula for gastric and intestinal fistulas. Proc. Soc. exp. Biol. (N.Y.), 46, 260-261. 